\title{
Nanocomposite C-Pd thin films - a new material with specific spectral properties
}

\author{
Małgorzata Suchańska $^{1 *}$, Hovik Baghdasaryan ${ }^{2}$, Justyna Kęczkowska $^{1}$ \\ ${ }^{1}$ Kielce University of Technology, al. 1000 -lecia P.P. 7, 25-314 Kielce, Poland. \\ ${ }^{2}$ State Engineering University of Armenia, 105 Terian str, Yerevan 0009, Armenia \\ "corresponding author: m.suchanska@tu.kielce.pl
}

\begin{abstract}
In this paper, the results of optical investigations for thin films of carbon-palladium (C-Pd) nanocomposites are presented. This films were prepared using two step PVD/ CVD method. The optical and Raman spectroscopy has been used to characterize the material. The multinanolayer model was used to explain the specific spectral properties.
\end{abstract}

\section{Introduction}

Findings of novel materials with specific spectral properties are very interesting from both fundamental and technological points of view and will inspire designs of new photonic devices.

Nanocomposite C-Pd thin films are becoming an interesting object of studies thanks to their electrical features $[1,2]$. However, there is much less information concerning the optical properties of such structures. For this reason, the preparation and studies of carbon-metallic nanocomposites are becoming vital for seeking materials with controllable band structure and optical properties. In recent years new nanocomposites containing palladium and carbon nanostructures have been prepared in Tele- and Radio Research Institute [3,4]. Optical properties of these carbonpalladium samples (C-Pd samples) have been investigated by our group [5].

In this paper the study of dependences between the nanocomposite structure and its optical properties were performed using optical transmission spectroscopy (OS) and Raman Spectroscopy (RS). An attempt of theoretical approach to facilitate an understanding of specific optical properties of nanocomposite C-Pd thin film in UV-MIR range is presented.

\section{Experimental}

The technology of obtaining C-Pd films using a two-step method was developed in the Tele \& Radio Research Institute in Warsaw. In the first step of the process (PVD method) the films constituting the matrix for structures obtained in the second step (CVD method) are created. Depending on the technological parameter of each process we obtain films with various weight percentage content of $\mathrm{Pd}$ and various structure defect degree. The detailed information on the technological process can be found in works $[3,4]$. The films obtained in first step (PVD) are a carbon-palladium nanocomposite where palladium nanograins are embedded in the carbonaceous matrix. In second step (CVD) the porous structure is obtained.

The Raman spectra measurements were carried out using Jobin Yvon-Spex T64000 Raman spectrometer with triple-grid monochromator, equipped with confocal microscope and CCD detector (with the resolution of $1024 \mathrm{x}$ 256 pixels) cooled with liquid nitrogen. For the measurements the single monochromatisation was applied, with Rayleigh dispersion used effectively by Notch-type filters. The measurements were carried out in ambient temperature for the excitation wavelength of $514,5 \mathrm{~nm}$. Acquisition of spectra was performed for spectral range 150 do $3500 \mathrm{~cm}^{-1}$. The transmission spectra measurement was carried out by means of Cary 5000 dispersion spectrophotometer in the range from $200-3500 \mathrm{~nm}$, with the resolution of $1 \mathrm{~nm}$.

\section{Results and discussion}

\subsection{Raman study}

The Raman spectroscopy investigations of PVD samples give us an information that carbonaceous matrix consists of different allotropic forms of carbon. In the measured range (from 150 to $2000 \mathrm{~cm}^{-1}$ ) the bands characteristic of $\mathrm{C}_{60}$ fullerene, graphite and amorphous carbon ( $\mathrm{G}$ and $\mathrm{D}$ bands) were observed (Fig. 1). The location of characteristic bands in the spectra confirms the dominance of the fullerite structure in such type of samples. The shapes of spectra for samples with different contents of Pd (\% wt.) are highly similar. 


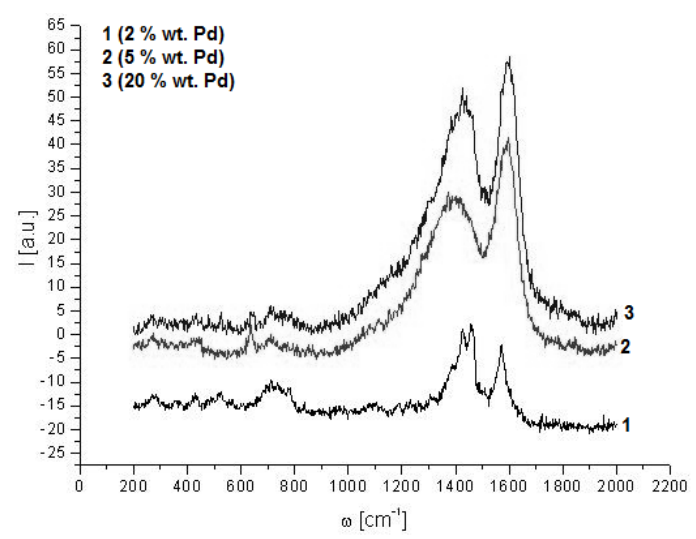

Figure 1. Raman spectra of C-Pd films with various $\mathrm{Pd}$ contents, obtained in PVD.

In the Raman spectra obtained using CVD method D and $\mathrm{G}$ bands, as well as the additional bands in the range of 2000-3500 $\mathrm{cm}^{-1}$ were observed (Fig. 2). The other four bands isolated in the analysis in the range of $1900-3500 \mathrm{~cm}^{-}$ ${ }^{1}$ may result from the carbon-hydrogen or oxygen-hydrogen interactions $[6,7]$.

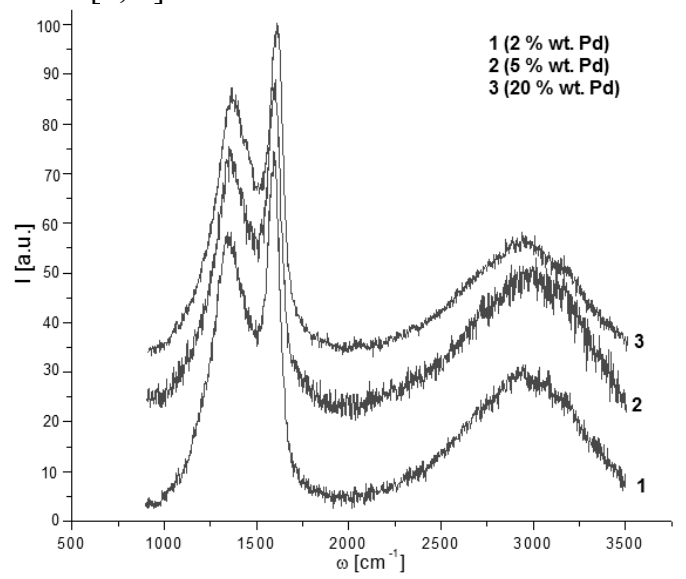

Figure 2. Raman spectra of C-Pd films with various $\mathrm{Pd}$ contents, obtained in CVD.

\subsection{Optical study}

In Fig. 3 the optical transmittance spectra for PVD (1) and CVD (2) samples are presented. A shape of dependence transmittance on wavelength is different for PVD (1) and CVD (2) samples. PVD samples are characterized with a very low absorption coefficient in IR range and a high value of this coefficient in the UV - VIS range. For CVD samples the absorption coefficient in IR range higher them for PVD samples.

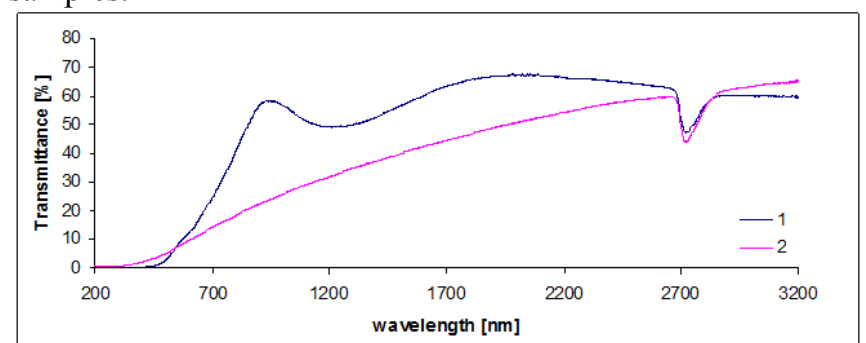

Figure 3. Transmittance spectra of PVD (1) and CVD (2) samples.
UV-VIS spectroscopy of fullerenes indicates the presence of strong absorption bands in the range from 200$400 \mathrm{~nm}$, related to the electron transition in $\mathrm{C}_{60}$ molecule structure [8].

Near $2700 \mathrm{~nm}(0.45 \mathrm{eV})$, a strong absorption band originating from the silica substrate is observed. In NIR region the transmittance coefficients are subject to the quasiperiodic modulation resulting from the interference on the boundaries of the carbon-palladium layer. The location of the local minimums and maximums varies for particular samples which may confirm the diversified sample thickness and/or various values of the layer refractive effective coefficient neff. The minimum optical transmittance coefficient value falls for the wavelength values where the wave reflected from the layer-air boundary is phasecoincident with the wave reflected on the layer-substrate boundary.

To analyze spectral characteristics of C-Pd PVD/CVD composite (of overall thickness $\approx 300 \mathrm{~nm}$ ) deposited on $\mathrm{SiO}_{2}$ substrate $(\approx 1 \mathrm{~mm}$ thickness $)$ is suggested to exploit multinanolayers approach. For this analysis the method of single expression is used [9].

\subsection{Theoretical model}

Till mow for modelling metal-dielectric nanocomposites the well-known approach of effective permittivity (so called Maxwell Garnet approach) is used $[10,11]$. This approach is applicable exclusively for spherical nanoparticles at low weight ratio $[10,11]$. However microscopic analysis of $\mathrm{C}$ $\mathrm{Pd}$ nanocomposites indicates, that the forms of $\mathrm{Pd}$ nanoparticles in $\mathrm{C}-\mathrm{Pd}$ nanocomposites are far to be spherical, what makes the Maxwell Garnet approach inadequate for C-Pd nanocomposites treatment.

In the present work as an alternative is suggested to model thin C-Pd nanocompsite by the help of an appropriate multinanolayer structure. To have the model of a nanocomposite the nanolayers of $\mathrm{C}, \mathrm{Pd}$ and air gap are arranged in arbitrary way and many possible nanolayers alternations are considered. Average values of reflectance and transmittance are analyzed on subject of consistency with the experimental results. An advantage of this model is in correct solution of boundary problem by taking into account the thickness of substrate and boundaries of all nanolayers.

Modelling indicated, that application of known values for permittivity of bulk Pd [12] brings to the strong discrepancy with experimental results. The difference of permittivity of nanoparticles and bulk material is indicated in [9]. An influence of the shape of metallic nanoparticles on its permittivity is indicated in $[11,13,14]$.

In our modelling we consider the normal incidence of plane electromagnetic wave on a thin nanocomposite layer located on a $\mathrm{SiO}_{2}$ substrate. The nanocomposite is represented as a multinanolayer structure with random alternation of $\mathrm{C}, \mathrm{Pd}$ and air nanolayers. The thickness of constituting nanolayers has been varied:

$$
\begin{aligned}
& \mathrm{L}_{\mathrm{C} 60}=20-40 \mathrm{~nm} \\
& \mathrm{~L}_{\mathrm{Pd}}=10-30 \mathrm{~nm} \\
& \mathrm{~L}_{\text {air gap }}=10-30 \mathrm{~nm}
\end{aligned}
$$


On Fig. 4 one of the analysed structure is presented.

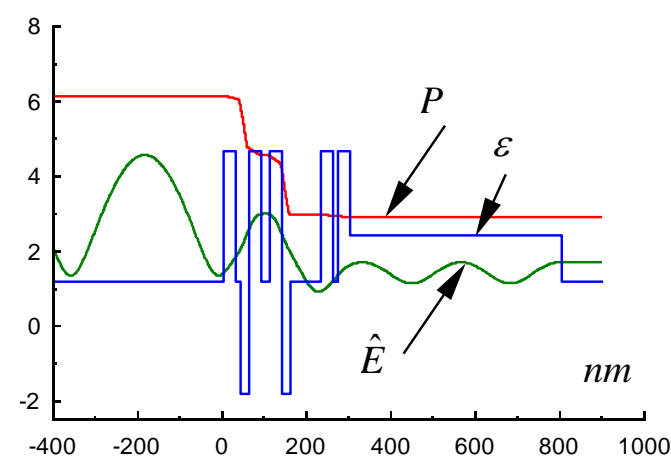

Figure 4. Normal incidence of plane electromagnetic wave (from the left) on the multinanolayer structure of overall thickness $300 \mathrm{~nm}$ located on a substrate of thickness 500nm. Distributions of permittivity $\varepsilon$, amplitude of electric field $\hat{E}$ and power flow density $P$ within and out of the structure is presented.

The wavelength of incident wave is:

$$
\begin{aligned}
& \lambda_{0}=700 \mathrm{~nm} \\
& \varepsilon_{\text {sub }}=2.25 \\
& \varepsilon_{C}^{\prime}=4.5 \\
& \varepsilon_{C}^{\prime \prime}=-0.1 \\
& \varepsilon_{P d}^{\prime}=-2 \\
& \varepsilon_{P d}^{\prime \prime}=-1.5 \\
& L_{C 60}=30 \mathrm{~nm} \\
& L_{P d}=20 \mathrm{~nm} \\
& L_{\text {air }}=10 \mathrm{~nm} .
\end{aligned}
$$

For the considered structure the reflectance and transmittance are $R=0.2967$ and $T=0.3305$ correspondingly. At this wavelength (near infrared) the main loss is take place in Pd nanolayers, what is visible as the sharp decrease of power flow $P$ on Fig. 4 .

The modelling indicated conditions when an agreement with the experiment is possible:

- an amount of complex permittivity of Pd nanoparticles will be taken essentially low than the permittivity of bulk Pd;

- the values of complex permittivity of $\mathrm{C}_{60}$ fullerene, known from the literature [15], are satisfactory for modelling.

The outcome from the modelling:

- the nanoparticles Pd having arbitrary shape cannot be modeled by using the permittivity values for bulk Pd;

- the main contribution in loss within the structure is stipulated by $\mathrm{C}_{60}$ fullerene, what observed as low transmittance in UV range (200-400nm) and in increase of transmittance at IR range;

- the difference in transmittance for PVD and CVD structures is stipulated by the presence of air gaps in CVD structures. Within the air gaps the field amplitude is higher relatively to the other nanolayers of a structure. This brings to the increase of loss in neighbour layers of $\mathrm{C}_{60}$ fullerene and $\mathrm{Pd}$;
- an observed in experiments sharp decrease of transmittance at 2700nm (on Fig. 3) is not stipulated by the structure and rather by the specific chemical composition of the substrate.

\section{Conclusions}

In conclusion, the suggested model of multinanolayer structure is pertinent for analysis thin metal-dielectric nanoporous materials and can be considered as an alternative to the well-known methods of modelling.

An influence of presence different allotropic forms of carbon and $\mathrm{Pd}$ nanocrystallites on spectral characteristics observed in experiment is discussed.

Based upon our experiments we can conclude that advantage of nanocomposite C-Pd thin films is a unique opportunity to monitoring optical properties by technological parameters. Theoretical analysis of the results and further research would be also useful for better understanding specific optical properties of nanocomposite carbon-metal composite thin films.

\section{Acknowledgements}

This research was performed in the framework of the EU COST Action MP0702 and financed by Polish Ministry of Science and Higher Education (577/N-COST/2009/0 research project).

\section{References}

[1] E. Czerwosz,P. Dłużewski, J. Kęczkowska, M. Kozłowski, M.. Suchańska and H. Wronka, Palladium nanocrystals and their properties, Materials SciencePoland vol. 26 (1), 119-125, 2008.

[2] E. Czerwosz, Badania zmian własności przewodnictwa elektrycznego warstw palladowo-węglowych pod wpływem gazów zawierających związki wodoru, Przeglad Elektrotechniczny 10: 61-64, 2010.

[3] M. Kozłowski, R. Diduszko, K. Olszewska, H. Wronka and E. Czerwosz, Nanostructural palladium films for sensor applications, Vacuum 82: 956-961, 2008.

[4] E. Kowalska, E. Czerwosz and J. Radomska, Metoda syntezy nanoporowatych materiałów węglowopalladowych, Elektronika 1: 32-35, 2009.

[5] R. Belka, M. Suchańska, E. Czerwosz, A. Chiasera and M. Ferrari, The optical study of nanoporous $\mathrm{C}=\mathrm{Pd}$ thin films, Proceeding of SPIE 7502: 750223, 2011

[6] P. K. Chu, L. Li: Characterization of amorphous and nanocrystalline carbon films; Materials Chemistry and Physics 96: 253-277, 2006.

[7] M. Yoshikawa, G. Katagiri, H. Ishida, A. Ishitani, T. Akamatsu, Raman spectra of diamond like amorphous carbon films, J. Appl. Phys. 64: 6464-6468, 1988.

[8] G. Orlandi, F. Negri, Electronic states and transitions in $\mathrm{C}_{60}$ and $\mathrm{C}_{70}$ fullerenes, Photochem. Photobiol. Sci. 1: 289-308, 2002.

[9] H. V. Baghdasaryan, T.M. Knyazyan, Problem of Plane EM Wave Self-action in Multilayer Structure: an Exact 
Solution, Optical and Quantum Electronics 31: 10591072, 1999.

[10] J.C. Maxwell Garnet, Phil. Trans. 203: 385, 1904; ibid. 205: 237, 1906.

[11] O.S. Heavens, Optical properties of thin solid films, Dover publ. Inc., 1991.

[12] http://refractiveindex.info

[13] P.N. Prasad, Nanophotonics, Wiley-Interscience, 2004.

[14] S.V. Gaponenko, Introduction to Nanophotonics, Cambridge University Press, 2010.

[15] K.H. Hiromichi et.al, Dielectric constants of $\mathrm{C}_{60}$ and $\mathrm{C}_{70}$ - thin films, J. Phys. Chem. Solids, 58: 19-23, 1997 